Sixth Symposium on Separation Science and Technology for Energy Applications,

Knoxville, Tennesee, October 22-26, 1989

\title{
APPLICATION OF SUPPORTED LIQUID MEMBRANES FOR REMOVAL OF \\ URANIUM FROM GROUNDWATER*
}

BY

R. Chiarizia, E. P. Horwitz, and P. G. Rickert

Argonne National Laboratory,

and

K. M. Hodgson, Westinghouse/Hanford
CONF-891013--4

DE90 001941

\section{Abstract}

The separation of uranium from Hanford site groundwater was stucied by hollow-fiber supported liquid membranes, SLM. The carrier bis(2,4,4-trimethylpentyl)phosphinic acid, H[DTMPep], contained in the commercial extractant Cyanex ${ }^{\mathrm{TM}} 272$ was used as membrane carrier, because of its selectivity for $U$ over crilcium and magnesium. The water soluble complexing agent, 1-hydroxyethane1,1-diphosphonic acid, HEDPA, was used as stripping agent. Polyproylene hollow-fibers and n-dodecane were used as polymeric support and diluent, respectively. Laboratory scale hollow-fiber modules were employed in a recycling mode, using as feed synthetic groundwater at $\mathrm{pH} 2$, to confirm the capability of the proposed SLM system to separate and concentrate $U(V I)$ in the strip solution. information was obtained on the $U(V I)$ concentration factor and on the long-term performance of the SLMs. Encouraging results were obtained both with a conventional module and with a module containing a carrier solution reservoir. Industrial scale modules were used at Hanford to test the SLM separation of $U(V I)$ from real contaminated groundwater. The uranium cuncentration was reduced from approximately $3,500 \mathrm{ppb}$ to about $1 \mathrm{ppb}$ in a few hours.

"This work was supported by Westinghouse Hanford Company under Contract No. MFBSNV-577854. 


\section{INTRODUCTION}

In a previous study (1) we reported on the application of a supported liquid membrane system for the removal of uranium(VI) from contaminated groundwater. We demonstrated that the carrier bis(2,4,4-trimethylpentyl)phosphinic acid (H[DTMPeP]), contained in the commercial extractant Cyanex ${ }^{\top M} 272$, was very effective in removing uranium (VI) from synthetic groundwater acidified to $\mathrm{pH}$ 2 with sulphuric acid, and that the separated uranium could be stripped and concentrated in a solution containing 1-hydroxyethane-1,1-diphosphonic acid (HEDPA). The SLM system is schematically shown in Fig. 1.

The SLM study reported in ref. (1) was performed using flat-sheet polymeric supports for the membrane, because the main goal of that investigation was to establish the best chemical conditions for the desired separation. For a practical application of a SLM based separation, however, hollowfiber polymeric supports are more effective because of their more favorable ratio of membrane area to volume of circulating solutions.

In ref. (2) Danesi demonstrated that the same equations holding for flat-sheet SLMs can be used in the case of hollow-fiber membranes operated in a recycling mode, providing the flow rate through the fibers is high enough. These equations, derived in (3), are summarized below. The permeability coefficient of the permeating species is related to distribution and diffusion parameters by

$$
P=J / C=\frac{K_{d}}{K_{d} \Delta_{a}+\Delta_{0}}
$$

witt: $P=$ permeability coefficient, $\mathrm{cm} \mathrm{s}^{-1}$

$J=$ flux of the permeating species, $\underline{M} \mathrm{~s}^{-1} \mathrm{~cm}$

$C=$ feed concentration, $\underline{M}$

$\mathrm{K}_{\mathrm{d}}=$ distribution ratio of the metal species between the membrane solution and the feed solution

$\Delta_{\mathrm{a}}=\mathrm{d}_{\mathrm{a}} / \mathrm{D}_{\mathrm{a}}=$ thickness of aqueous diffusion layer/aqueous diffusion coefficient, $\mathrm{cm}^{-1} \mathrm{~s}$ 


$$
\begin{aligned}
\Delta_{0}=\mathrm{d}_{0} / \mathrm{D}_{\mathrm{o}}, \text { app } & =\text { membrane thickness/apparent diffusion coefficient of the permeating species } \\
& \text { in the membrane, } \mathrm{cm}^{-1} \mathrm{~s} .
\end{aligned}
$$

The diffusional parameter $\Delta_{\mathbf{a}}$ is the reciprocal mass transfer coefficient of the diffusion species in the aqueous diffusion film.

The flux is defined as:

$$
J=-\frac{d C}{d t} \times \frac{V}{A}
$$

where $V$ is the volume of the feed solution and $A$ the membrane area. The integration of eq. (2) leads to:

$$
\ln \frac{C}{C_{o}}=-\frac{A}{V} P t
$$

where $C_{0}$ is the value of $\bar{c}$ at time zero.

Equations (1) and (3) are very useful for predicting the behavior of SLMs. However, to apply eqs. (1) and $(3)$ the following limiting conditions must exist: the distribution ratio at the membraneaqueous strip interface is much lower than at the membrane-aqueous feed interface, the interfacial chemical reactions are fast, and the concentration of the permeating species is much lower than that of the carrier (3). These limiting conditions are all met in the application of our SLM system for the uranium (VI) removal from groundwater.

In this work we have extended our investigation to the uranium (VI) transport through hollowfiber supported liquid membrares with the following objectives:

- to verify, with small laboratory scale hollow-fiber modules, the validity of the results obtained with flat-sheet supports;

- to demonstrate that high concentration factors of $U(V I)$ can be achieved;

- to obtain information on the long-term stability of the hollow-fiber SLMs;

- to test the developed liquid membrane system with real contaminated groundwater, using commercial hollow-fiber membrane modules. 


\section{EXPERIMENTAL}

\section{Groundwater}

Several liters of synthetic Hanford site groundwater (SGW) were prepared as reported in (1). After addition of enough concentrated sulfuric acid to bring the $\mathrm{pH}$ value to about 2 , the resultant mixture had the composition reported in Table 1 . The solution simulates the composition of contaminated groundwater from well W19-11 acidified to $\mathrm{pH}=2$ using sulfuric acid.

Real Hanford site groundwater was pumped from the monitoring well 2-W19-3. The expected composition of the groundwater, based on samples taken in December 1987 is given in Table 2 . The uranium concentration $\left(8,590 \mathrm{ppb}=3.61 \times 10^{-5} \underline{\mathrm{M}}\right)$ was much higher than the Maximum Contaminant Limit $\left(10 \mathrm{ppb}=4.20 \times 10^{-8} \underline{\mathrm{M}}\right)$.

\section{Reagents}

Cyanex ${ }^{\mathrm{TM}} 272$, the membrane carrier for $\mathrm{U}(\mathrm{VI})$, was obtained from American Cyanamid Company and used as received. n-Dodecane was used as the diluent for Cyanex ${ }^{\mathrm{TM}} 272$, because it is known to interact only slowly with the support material (4). $0.1 \underline{M}$ Cyanex in n-dodecane was used as liquid membrane throughout this work.

1-Hydroxyethane-1,1-diphosphonic acid, HEDPA, was obtained from Albright and Wilson as a concentrated aqueous solution. It was recrystallized from glacial acetic acid. A $0.1 \underline{M}$ solution of HEDPA was used as strip solution, when not otherwise specified.

Vinylidene-1,1-diphosphonic acid, VDPA, was prepared and purified as described in (5). It was also used as stripping agent in some stability experiments.

All other reagents were analytical grade and were used without further purification.

\section{DISCLAIMER}

\footnotetext{
This report was prepared as an account of work sponsored by an agency of the United States Governnient. Neither the United States Government nor any agency thereof, nor any of their employees, makes any warranty, express or implied, or assumes any legal liability or responsibility for the accuracy, completeness, or usefulness of any information, apparatus, product, or process disclosed, or represents that its use would not infringe privately owned rights. Reference herein to any specific commercial product, process, or service by trade name, trademark, manufacturer, or otherwise does not necessarily constitute or imply its endorsement, recommendation, or favoring by the United States Government or any agency thereof. The views and opinions of authors expressed herein do not necessarily state or reflect those of the United States Government or any agency thereof.
} 


\section{Radioisotopes}

The stock solutions of ${ }^{233} \mathrm{U},{ }^{45} \mathrm{Ca}$, and ${ }^{59} \mathrm{Fe}$ were the same as in (1). Small aliquots of the tracer stock solutions were used, when necessary, to spike the feed solutions for the permeation experiments.

\section{Hollow-fibers}

Hollow-fiber supports were obtained from ENKA in the forrin of a MICROSTAT cartridge. The cartridge was disassembled and the hollow-fibers were used to fabricate small laboratory modules. Hollow-fiber supports, 7 to $14 \mathrm{~cm}$ long, containing from 4 to 100 fibers, were fabricated by inserting the desired number of fibers into a glass hollow tube having a side opening at each extreme. The fibers were sealed into the tube with an epoxy resin ( 5 minutes curing time). The epoxy seal extended into the tube for a few millimeters, providing complete isolation of the feed and strip aqueol:s solutions.

The liquid membrane was sorbed on the hollow-fibers by flowing, at a slow rate, the organic solution through the fiber lumen and then rinsing the lumen several times with distilled water to eliminate any excess of organic solution.

For the tests performed at Hanford with real groundwater, large size commercial ENKA modules were used.

The characteristics of the home-made laboratory scale modules used at Argonne and of the commercial modules used at Hanford are summarized in Table 3.

\section{Permeation Experiments}

All hollow-fiber modules were operated in a recirculating mode as shown schematically in Fig. 2. The feed and strip solutions were circulated through the lumen and on the shell side of the fibers, respectively, by means of calibrated peristaltic pumps. The permeation of the radionuclides through the SLM was followed by periodically sampling the feed and/or strip solution. The analyses were performed by gamma $\left({ }^{59} \mathrm{Fe}\right)$ and liquid scintillation $\left({ }^{233} \mathrm{U},{ }^{45} \mathrm{Ca}\right)$ counting techniques. The data were 
plotted on semilogarithmic scales as feed activity vs time. In the case of $233 U$ the data were corrected from non-uranium activity following the procedure reported in (1). From the slope of the straight line, the permeability coefficient $(P)$ in $\mathrm{cm} \mathrm{s}^{-1}$, was calculated according to eq. (3). The membrane area was calculated as

$$
A=2 \pi r N L
$$

where $r$ is the internal radius of the hollow-fibers, $N$ is the number of fibers and $L$ their length. Some experiments were performed with large volumes of feed solution ( 2 liters) to demonstrate the possibility of concentrating uranium in the strip solution. The membrane module used with 2 liter feed contained 100 fibers, each $13 \mathrm{~cm}$ long, and was fabricated as described previously. The uranium analyses were performed by laser induced fluorescence.

In the experiments aimed at the determination of the long-term membrane stability, a hollowfiber module was reimpregnated several times, at time intervals of about two months, by following the procedure described in detail in ref. (6).

A module containing a carrier reservoir was also fabricated and operated according to the indications provided in refs. (6) and (7). It contained 10 fibers, each $13.4 \mathrm{~cm}$ long, with the top 3.2 $\mathrm{cm}$ in contact with about $4 \mathrm{~cm}^{3}$ of carrier solution contained in a sealed reservoir, placed at the top of the module.

For the tests performed at Hanford using real groundwater as feed, a test stand was designed to operate two $2.2 \mathrm{~m}^{2}$ modules in series, in parallel or one module at a time. The test stand, shown in Fig. 3, is $150 \mathrm{~cm}$ high and $150 \mathrm{~cm}$ long, and consists of one feed tank, two strip tanks, three pumps, three rotameters, four thermocouples, and four pressure transducers. In each of the Hanford tests the volumes of the feed and strip solutions were 50 and 4 gallons, respectively. 


\section{BESULTS AND DISCUSSION}

\section{Permeation Studies}

Permeation experiments of $U(V I), C a(I I)$, and $\mathrm{Fe}(I I I)$ have been performed with hollow-fiber supports assembled in laboratory-scale modules. The chemical conditions were the same as in the flat-sheet experiments, i.e., SGW at $\mathrm{pH} 2$ was used as feed, $0.1 \underline{\mathrm{M}}$ HEDPA as strip, and $0.1 \underline{M}$ Cyanex 272 as liquid membrane.

Figure 4 reports a typical experiment as feed uranium activity vs time. The module used in this experiment contained 4 fibers $13 \mathrm{~cm}$ long, for a total membrane area of $9.8 \mathrm{~cm}^{2}$. The feed had a volume of $13 \mathrm{~mL}$ and was circulated at a flow rate $Q_{T}=8.5 \mathrm{~mL} / \mathrm{min}$. As expected from eq. (3), the data are well aligned on a stra:ght line up to a $99 \%$ removal of uranium from the feed.

The optimum hydrodynamic conditions for the modules used in this work were properly identified by studying the uranium permeability as a function of the flow rate of the feed solution (lumen side). The data, reported in Fig. 5, show that a constant $\mathrm{Pu}$ value was reachect for a feed solution with a linear velocity equal to about $8 \mathrm{~cm} \mathrm{~s}^{-1}$. At $8 \mathrm{~cm} / \mathrm{sec}$, the thickness of the aqueous diffusion film $\left(d_{a}\right)$ is minimized and a further increase of flow rate does not increase Pu. Furthermore, high feed velocities can be detrimental to the membrane stability. Extremely high flow rates can force the carrier solution out of the membrane pores by the excessive pressure exerted by the circulating liquid.

We have shown in (1) that, by plotting the uranium permeability coefficient as a function of the carrier concentration on flat-sheet supports, a "plateau" $P$ value equal to $1.0 \times 10^{-3} \mathrm{~cm} \mathrm{~s}^{-1}$ was reached for [Cyanex $\left.{ }^{\top M} 272\right] \geq 3 \times 10^{-3} \underline{\mathrm{M}}$. In these chemical conditions the transport of $U(\mathrm{VI})$ through the membrane is controlled only by the diffusion of uranium species through the aqueous phase diffusion layer at the feed-membrane interface.

From the data of Fig. 5, obtained at $0.1 \mathrm{M}$ carrier concentration, one can see that, with hollow-fibers, the "plateau" value of $P$ is $8.1 \times 10^{-4} \mathrm{~cm} \mathrm{~s} \mathrm{~s}^{-1}$, which is somewhat lower than the value obtained with flat-sheet supports. Differences in $P$ values obtained with flat sheets and hollow fibers 
are attributed to the different thickness of the aqueous diffusion film because of the different hydrodynamic conditions.

Essentially the same values of the membrane selectivity coefficients for uranium(VI) over $\mathrm{Ca}(\mathrm{II})$ and $\mathrm{Fe}(\mathrm{III}), \alpha_{\mathrm{U} / \mathrm{Ca}}^{\mathrm{M}}$ and $\alpha_{\mathrm{U} / \mathrm{Fe}}^{\mathrm{M}}$, defined as the ratio of the respective permeability coefficients, were obtained using hollow-fibers or flat-sheet supports. Data in Table 4 have been calculated by using the permeability coefficient of $\mathrm{U}(\mathrm{VI})$ and the selectivity values for $\mathrm{U}(\mathrm{VI})$ over $\mathrm{Ca}(\mathrm{II})$ and $\mathrm{Fe}(\mathrm{III}$ ). These data show the uranium separation from SGW achievable as a function of time for a SLM process using the chemical and hydrodynamical conditions and the membrane area to feed volume ratio used in obtaining the data of Fig. 5. For a different and much higher valus of the area/volume ratio, as usually provided by industrial hollow-fiber modules, the time required for a uranium separation would be correspondingly lower, but the relative contamination of uranium with calcium and iron, that depends on the selectivity, would be the same.

\section{Uranium Concentration Factor.}

By combining the extraction and stripping $U(V I)$-carrier reactions taking place at the feedmembrane and at the strip-membrane interface, respectively, it is possible to show that, at equilibrium, that is when no net transport of metal takes place in either direction, and assuming the metal to be always at tracer concentration level, uranium (VI) can be concentrated in the strip solution up to about $10^{8}$ times. Such a calculation requires the knowledge of the equilibrium constants for the $U(V I)-C y a n e x^{T M} 272$ reaction and for the U(VI)-HEDPA aqueous complexation reaction. The values of these constants have been reported in (1).

The very high concentration factor mentioned above is only theoretical. In practice, the uranium concentration in the feed and strip solutions is not at a tracer level and mass balance and solubility requirements will strongly reduce the achievable concentration factor.

With hollow-fiber modules operated in a recycling mode, the concentration of the transported species into the strip solution is achieved by recirculating a strip solution with a much smaller volume than the feed. Assuming a total transfer of metal, the concentration factor is simply given by the ratio 
of the feed to strip volumes. The same strip solution can be used over and over again until a very high metal concentration is reached. For example, we have demonstrated in (1) that a $1 \underline{M}$ HEDPA solution, containing $U(V I)$ at a concentration as high as $0.5 \underline{M}$, was still effective in stripping uranium from a 0.1 Cyanex 272 solution in n-dodecare.

To demonstrate that high concentration factors or $\mathrm{U}(\mathrm{VI})$ can be reached in practice with our hollow-fiber modules, the experiment reported in Fig. 6 has been performed. In this experiment a module containing 100 fibers, each $13 \mathrm{~cm}$ long, with a total calculated membrane area of $245 \mathrm{~cm}^{2}$, was used. The feed was a 2 liter solution of SGW circulated in the lumen of the fibers, while the strip solution volume was $45 \mathrm{~mL}$ (the minimum volume required to fill the shell side of the module and the tubing connections to the pump).

From the data of Fig. 6 , a Pu $=5.8 \times 10^{-4} \mathrm{~cm} \mathrm{~s}^{-1}$ was calculated. This $\mathrm{Pu}$ value is lower than the expected value of $8.1 \times 10^{-4} \mathrm{~cm} \mathrm{~s}^{-1}$, showing that probably the effective membrane area was lower than the calculated. When the experiment was interrupted after six hours, uranium had been concentrated by a factor of 34 in the strip solution.

\section{Membrane Stability Studies.}

Membrane stability experiments were performed with the objective of testing the ability of our hollow-fiber modules to continuously operate at high efficiency. The criteria for stability was a constant PU. Two modules were used in these experiments. The first one contained 10 fibers, 10.2 $\mathrm{cm}$ long. The second one contained 10 fibers, $13.4 \mathrm{~cm}$ long, with $3.2 \mathrm{~cm}$ of the fiber length in contact with $4 \mathrm{~cm}^{3}$ of the carrier solution confined in a sealed reservoir placed at the top of the module. SGW at $\mathrm{pH} 2$ was continuously circulated in the lumen of the fibers, while $0.1 \underline{\mathrm{M}}$ HEDPA was continuously circulated in the shell side of the modules. The circulation of feed and strip solutions was inierrupted only during nights and weekends. Every day the feed solution $(10 \mathrm{~mL})$ was replaced with fresh SGW, while the strip solution was replaced every month. Every few days the feed in both

modules was spiked with ${ }^{233} \mathrm{U}$ and the transport of uranium through the SLM was followed using the 
usual procedure. Data have been collected over several months and are reported in Fig. 7 as $\mathrm{PU}$ vs time for both the module with reservoir (MR) and the conventional module (CM).

We found that the $\mathrm{CM}$ module lost about $50 \%$ of its initial permeability in two months. At that point the experiment was stopped and the module was reimpregnated following the procedure reported in (6). The decline of the uranium permeability coefficient was followed again for a few months and the module was again reimpregnated. The whole procedure was repeated seven times over a total time span of almost 1.5 years. For each of the first three reimpregnations a progressively higher $P$ value was measured with the freshly reimpregnated module, up to a $P$ value almost twice as high as the initial one $\left(1 . \Xi \times 10^{-3} \mathrm{~cm} \mathrm{~s}^{-1}\right.$ vs $\left.8.5 \times 10^{-4} \mathrm{~cm} \mathrm{~s}^{-1}\right)$. This fact seems io confirm that some kind of interaction does take place between support and carrier solution (4), leading, in the long run, to a change in some support properties that in turn affect the permeabivity. A progressively more evident swelling of the fibers, for example, was observed in the CM module, with increased fiber length and membrane area. The stability of the membrane, however, did not seem to be affected by the reimpregnations, because the reimpregnated membrane did not behave differently from the original one. It is interesting that the $\mathrm{CM}$ module described in Fig. 7 lost about $50 \%$ of its initial uranium permeability after $6 \times 10^{5}$ fiber volumes had circulated through it. This value lies between the values $5 \times 10^{4}$ of ref. (8) and $5 \times 10^{6}$ of ref. (3) for similar systems, and is representative of a very stable SLM system.

In the permeation experiments performed after the last two reimpregnations, different strip solutions were used. In one case, $1 \underline{\mathrm{M}}$ instead of $0.1 \underline{\mathrm{M}}$ HEDPA was used to measure the effect of a high osmotic pressure gradient between feed and strip solutions on the stability of the membrane. The data do not show any significant decrease in stability, at least over the time interval explored, confirming that a more concentrated solution of the stripping agent can be used, which in turn means that a higher concentration factor can be reached. Similar results were obtained using $1 \underline{M}$ VDPA as the stripping solution. The use of VDPA instead of HEDFA is recommended if a process utilizing our suggested SLM system is implemented for the decontamination of groundwater. VDPA belongs to 
the family of TUCS (thermally unstable complexing and stripping agents) compounds at present under investigation at ANL (5). It is almost as powerful as its parent compound, HEDPA, as a U(VI) complexing agent, and is much easier to decompose by oxidation and heating, leaving the isolated uranium as a phosphate salt.

The MR module, equipped with a continuous reimpregnation system, performed remarkably well, which was expecteci from studies reported in refs. (6) and (7). We found that uranium permeability for MR actually increased by about $20 \%$ over a time span of about 110 days. The increase in Pu could be due to the same changes in membrane orengr.:s that prosusas d yiler permeability with the CM module after reimpregnation. Two minor problems were, however, associated with the use of a reservoir. First, it was necessary to add periodically small amounts (about $1 \mathrm{~mL}$ every $2-3$ weeks) of carrier solution into the reservoir. It is likely that the carrier solution slowly diffuses through the fiber walls and is released to the ieed and/or strip solution. This fact does not have any influence on the $\mathrm{PU}$ and, actually, ensures that the support pores are always filled with relatively fresh liquid membrane solution. Second, some uranium accumulates in the reservoir solution, as revealed by analysis of periodic samples withdrawn through a suitable opening of the reservoir chamber. The uranium was extracted into the reservoir because the feed solution was circulated through the lumen side of the fibers. By circulating, instead, the feed solution on the shell side and the strip solution on the lumen side of the SLM module, reservoir contamination could probably be eliminated.

The stability experiment with the self-impregnating MR module was interrupted after about six months, because the reservoir seal deteriorated and the carrier solution leaked out. However, it worked long enough to demonstrate that a properly designed selt-impregnating module can operate for a practically unlimited time.

\section{Tests with Real Groundwater}

Two tests were performed at Hanford using the test stand shown in Fig. 3 and groundwater from the 216-U-1,2 cribs (monitoring well 2-W19-3). The purpose of these tests was to demonstrate, using contaminated groundwater acidified to $\mathrm{pH} 2$ with sulfuric acid, the SLM uranium removal 
process developed at Argonne on a laboratory scale. The $2.2 \mathrm{~m}^{2}$ commercial module described in Table 3 was used after impregnation with a $0.1 \underline{M}$ solution of Cyanex ${ }^{\top M} 272$ in $n$-dodecane. The strip solution was 4 gallons of $0.1 \mathrm{M}$ HEDPA. In each run 50 gallons of groundwater were used as feed and circulated on the shell side of the module. The results of the first run are reported in Fig. 8 , as feed uranium concentration ( $\mathrm{ppb}$ ) vs time. The data show that the uranium concentration in the groundwater was reduced from $\cong .460 \mathrm{ppb}$ to less than the Maximum Contaminant Limit (10 ppb) in less than twelve hours. Also, a straight line can be fit to the data indicating that the model described by eqs. (1)-(3) is valid for the module and feed conditions used in the test.

From the data of Fig. 8 a Pu $=5.9 \times 10^{-4} \mathrm{~cm} \mathrm{~s}^{-1}$ can be calculated. The somewhat lower value than $8.1 \times 10^{-4} \mathrm{~cm} \mathrm{~s}^{-1}$ reported in Fig. 5 is probably due to the poor hydrcdynamics attained when the feed is circulated on the snell side of the module. Tre tight packing of the fibers makes it difficult to get the linear velocity required next to the fibers to minimiza the aqueous diffusion layer. The second run showed, however, a better module performance, with a calculated $\mathrm{PU}=1.4 \times 10^{-3}$ $\operatorname{crn~s} \mathrm{s}^{-1}$.

The same stripping solution was used for both runs, so that the uranium contained in 100 gallons of groundwater was collected in 4 gallons of strip solution. A much higher uranium concentration factor can be achieved, however, by using the same strip solution for other runs.

Although it is not possible to determine cunclusively the scale up factor on only two runs, values obtained for the uranium permeability coefficients seem to indicate a scale up factor of one, as previously determined for the same kind of commercial modules in ref. (9).

\section{SUMMARY AND CONCLUSIONS}

We have demonstrated that a holiow-fiber supported liquid membrane system containing a carrier solution of the commercially available solvent extraction reagent Cyanex ${ }^{\top M} 272$ in dodecane is very effective in removing uranium from a synthetic groundwater at $\mathrm{pH} 2$. This relatively low $\mathrm{pH}$ value has tieen chosen to obtain an extremely high membrane selectivity over calcium and magnesium, 
which are the major constituents of the groundwater. The reagent 1-hydroxyethane-1,1diphosphonic acid (HEDPA) has been used as the stripping agent.

Permeating experiments, performed with small home-made hollow-fiber membrane modules have demonstrated the applicability of previously derived permeability equations to the problem of removing uranium from groundwater.

A uranium concentration factor of 34 has been demonstrated in membrane experiments. Based on the chemistry of the SLM separation investigated here, however, there is reason to believe that much higher concentration factors, of the order or at least $10^{3}$, can be achieved without particular difficulties.

Tests performed at Hanford with real groundwater and large size commercial hollow-fiber modules have been very successful in reducing the concentration of uranium below the Maximum Contaminant Limit of $10 \mathrm{ppm}$. The uranium contained in 100 gallons of groundwater was separated and concentrated in 4 gallons of strip solution.

Very encouraging membrane stability results have been obtained with a continuously selfimpregnating module with which constant uranium permeability values have been measured over a time period of more than 6 months.

li has also been shown, with a small conventional module, that tie periodic reimpregnation technique is effective in restoring and actually improving the membrane performance. This experiment has been followed for one and a half years, with seven reimpregnation of the fibers, without any apparent deterioration of the membrane support. During this experiment it has been shown that a strip solution containing a $1 \underline{M}$ concentration of the stripping agent can be used without affecting the membrane stability. Also, the use of the alternative stripping agent, vinylidene-1,1-diphc sphonic acid, VDPA, belonging to the family of TUCS compounds, and more easily decomposed than HEDPA, has been tested, with positive results.

Work is in progress concerning the use of similar SLM processes for the removal of other contaminants from the groundwater. 


\section{Acknowledgments}

The ANL authors wish to express their gratitude to Westinghouse Hanford Co. for the financial support provided. The authors also wish to thank K. L. Nash for providing the pure HEDPA, R.C. Gatrone for providing the VDPA, and $\mathrm{H}$. Diamond for help provided with radiochemical measurements.

\section{REFERENCES}

1. R. Chiarizia and E. P. Horwitz, Solvent Extr. Ion Exch., in press.

2. P. R. Danesi, J. Membr. Sci. 20, 231 (1984).

3. P. R. Danesi, Sep. Sci. Technol. 19, 857 (1985-84).

4. D. J. Chaiko and K. Asseo-Asare, Sep. Sci. Technol. 17, 1659 (1982-83).

5. R. C. Gatrone, E. P. Horwitz, P. G. Rickert, and K. L. Nash, A new class of reagents for use in nuclear waste processing. Synthesis and degradation, Sixth Symposium on Separation Science and Technology for Energy Applications, Knoxvilie, TN, October 22-26, 1989.

6. P. R. Danesi and P. G. Rickert, Solvent Extr. Ion Exch. 4, 149 (1986).

7. W. Klein, Coupled Transport. A New Separation Technology Emerging to the Market, ENKAInformation, May 1984.

8. D. Pearson, Supported Liquid Membranes for Metai Extraction from Dilute Solutions, from lon Exchange Membranes, D. S. Flett, Editor, Society of Chemical Industry, London, 1983, pp. 55-73.

9. W. R. Dvorzak and A. J. Naser, Sep. Sci. Technol. 22 (2-3), 677 (1987). 
Table 1. Somposition of SGW at $\mathrm{pH}=2$.

\begin{tabular}{ll}
\hline \hline Constituent & Molarity \\
Calcium & 0.012 \\
Magnesium & 0.0062 \\
Sodium & 0.017 \\
Silicon & 0.0009 \\
Chloride & 0.0016 \\
Sulfate-bisulfate & 0.017 \\
Nitrate & 0.030 \\
Uranium & 0.0004 \\
pH & 2.09 \\
Sum of molarities & 0.094 \\
\hline \hline
\end{tabular}


Table 2. Analysis of Water from Well 2-W19-03.

\begin{tabular}{|c|c|}
\hline Chemical Component & Concentrations \\
\hline Barium & $49 \mathrm{ppb}$ \\
\hline Calcium & $49,900 \mathrm{ppb}$ \\
\hline Chloride & $19,100 \mathrm{ppb}$ \\
\hline Copper & $12 \mathrm{ppb}$ \\
\hline Fiuoride & 965 ppb \\
\hline Iron & $245 \mathrm{ppb}$ \\
\hline Magnesium & $14,100 \mathrm{ppb}$ \\
\hline Manganese & $9.0 \mathrm{ppb}$ \\
\hline Nitrate & $93,000 \mathrm{ppb}$ \\
\hline $\mathrm{pH}$ & 7.92 \\
\hline Polassium & $4,630 \mathrm{ppb}$ \\
\hline Radium & $0.25 \mathrm{pCi} / \mathrm{L}$ \\
\hline Sodium & 77,100 ppb \\
\hline Specific conductance & 606 umho \\
\hline Strontium & $207 \mathrm{ppb}$ \\
\hline Sulfate & $55,400 \mathrm{ppb}$ \\
\hline TOXLDLa & $69 \mathrm{ppb}$ \\
\hline Tri-butyl phosphaie & $10 \mathrm{ppb}$ \\
\hline Carbon tetrachloride & $86 \mathrm{ppb}$ \\
\hline Total carbon & $44,800 \mathrm{ppb}$ \\
\hline Total organic carbon & 643 ppb \\
\hline Zinc & $15 \mathrm{ppb}$ \\
\hline Uranium & $8,590 \mathrm{ppb}$ \\
\hline \multicolumn{2}{|c|}{ (Sampled 12/09/87) } \\
\hline Total alpha & $3,930 \mathrm{pCi} / \mathrm{L}$ \\
\hline Total beta & $4,050 \mathrm{pCi} / \mathrm{L}$ \\
\hline Nitrate & $71,400 \mathrm{ppb}$ \\
\hline Cesium-137 & $5.08 \mathrm{pCi} / \mathrm{L}$ \\
\hline Cobalt -60 & $3.03 \mathrm{pCi} / \mathrm{L}$ \\
\hline Technetium-99 & $1,860 \mathrm{pCi} / \mathrm{L}$ \\
\hline
\end{tabular}

aToxic organic halogen-low detection limit. 
Table 3. Characteristics of the SLM modules used in this work.

Home-made

$9.8-245 \mathrm{~cm}^{2}$

0.6

1.0

200

$7-14$

75

4-100

0.1

polypropylene
Commercial

$2.2 \mathrm{~m}^{2}$

0.6

1.0

200

45.5

75

2,600

0.1

polypropylene 
Table 4. U(VI), Ca(II), and Fe(III Removal as a Function of Time from SGW at pH 2.

Conditions:

$$
\begin{aligned}
\text { Carrier } & =0.1 \underline{\mathrm{M}} \text { Cyanex }^{\mathrm{TM}} 272 \\
\text { Strip } & =0.1 \underline{\mathrm{M}} \text { HEDPA } \\
\text { membrane area } & =9.8 \mathrm{~cm}^{2} \\
\text { feed volume } & =13 \mathrm{~cm}^{3} \\
\text { feed linear velocity } & =8.0 \mathrm{~cm} \mathrm{~s}^{-1} \\
\mathrm{PU} & =8.1 \times 10^{-4} \mathrm{~cm} \mathrm{~s}^{-1} \\
\alpha_{\mathrm{U} / \mathrm{Ca}}^{\mathrm{M}} & =1.6 \times 10^{4} \\
\alpha_{\mathrm{U} / \mathrm{Fe}}^{\mathrm{M}} & =40
\end{aligned}
$$

\begin{tabular}{cccc}
$\begin{array}{c}\text { Uranium } \\
\text { removal } \\
\%\end{array}$ & $\begin{array}{c}\text { Time } \\
\text { min }\end{array}$ & $\begin{array}{c}\text { Calcium } \\
\text { removal } \\
\%\end{array}$ & $\begin{array}{c}\text { Iron } \\
\text { removal } \\
\%\end{array}$ \\
\hline 50.0 & 19 & 0.004 & 1.7 \\
90.0 & 63 & 0.014 & 5.5 \\
99.0 & 126 & 0.029 & 10.7 \\
99.9 & 188 & 0.043 & 15.7 \\
\hline \hline
\end{tabular}




\section{Figure Captions}

Fig. 1. Schematic of SLM for the removal of U(VI) from groundwater.

Fig. 2. Schematic description of a 4 hollow-fiber module operated in a recycling mode.

Fig. 3. Test stand used at Hanford for $U(V I)$ removal from groundwater.

Fig. 4. Typical uranium permeation experiment. Membrane area $=9.8 \mathrm{~cm}^{2}$ (4 fibers, $13 \mathrm{~cm}$ long); feed = SGW at pH 2, $13 \mathrm{~mL}$, circulated in the lumen side at $8.5 \mathrm{~mL} / \mathrm{min}$; strip $=0.1 \underline{\mathrm{M}} \mathrm{HEDPA}$, $18 \mathrm{~mL}$, circulated in the shell side at $8.5 \mathrm{~mL} / \mathrm{min}$.

Fig. 5. $P U, U(V I)$ permeability coefficient vs feed flow rate, $Q_{T}, \mathrm{~mL} \mathrm{~min}^{-1}$, or feed linear velocity, $\bar{U}$, $\mathrm{cm} \mathrm{s}^{-1}$. $Q_{T}$ and $\bar{U}$ are related by $Q_{T}=\bar{U}_{\pi r^{2}} N$, where $N$ is the number of fibers and $r$ their internal radius. Same conditions as in Fig. 4.

Fig. 6. Uranium(VI) permeation experiment with a high ratio of feed to strip volume. Feed $=\mathrm{SGW}$ at $\mathrm{pH} 2,3.6 \times 10^{-4} \underline{\mathrm{M}}$ in $\mathrm{U}(\mathrm{VI}) ;$ strip $=0.1 \underline{\mathrm{M}}$ HEDPA; membrarie $=0.1 \underline{\mathrm{M}}$ Cyanex ${ }^{\mathrm{TM}} 272 ;$ membrane area $=245 \mathrm{~cm}^{2}$ calculated with eq. (4); feed volume $=2 \mathrm{~L}$ (lumen); strip volume = $45 \mathrm{~mL}$ (shell); feed linear velocity $=7.1 \mathrm{~cm} \mathrm{~s}^{-1}\left(Q_{\mathrm{T}}=120 \mathrm{~mL} / \mathrm{min}\right)$; strip flow rate $=50 \mathrm{~mL} / \mathrm{min}$.

Fig. 7. Pu vs $t$ (months) for 2 hollow-fiber modules, one without a carrier reservoir (CM), the other with a carrier reservoir (MR). Conditions: feed $=S G W$ at $\mathrm{pH} 2,5 \times 10^{-4} \underline{\mathrm{M}}$ in U(VI), strip = see text; membrane $=0.1 \underline{\mathrm{M}}$ Cyanex ${ }^{\top M} 272 ;$ membrane area $=19.2 \mathrm{~cm}^{2}$ for $\mathrm{CM}, 25.2 \mathrm{~cm}^{2}$ for $\mathrm{MR}$, calculated with eq. (4); feed volume $=10 \mathrm{~mL}$, strip volume $=16 \mathrm{~mL}$; teed linear velocity $=8$ $\mathrm{cm} \mathrm{s}^{-1}\left(Q_{T}=13.6 \mathrm{~mL} / \mathrm{min}\right) ;$ strip flow rate $=20 \mathrm{~mL} / \mathrm{min}$.

Fig. 8. Feed uranium concentration (ppb) vs time. Feed $=50$ gallons groundwater (shell side); strip = 4 gallons $0.1 \underline{M}$ HEDPA (lumen side); membrane $=0.1 \underline{M}$ Cyanex ${ }^{\top M} 272$ in $n$-dodecane; membrane area $=3.71 \mathrm{~m}^{2}\left(2.2 \mathrm{~m}^{2}\right.$ internal area $)$; feed flowrate $=1.5 \mathrm{gal} / \mathrm{min}$; strip flow rate $=$ $1.0 \mathrm{gal} / \mathrm{min}$. Experiment performed using the test stand shown in Fig. 3. 


$$
F: 1
$$

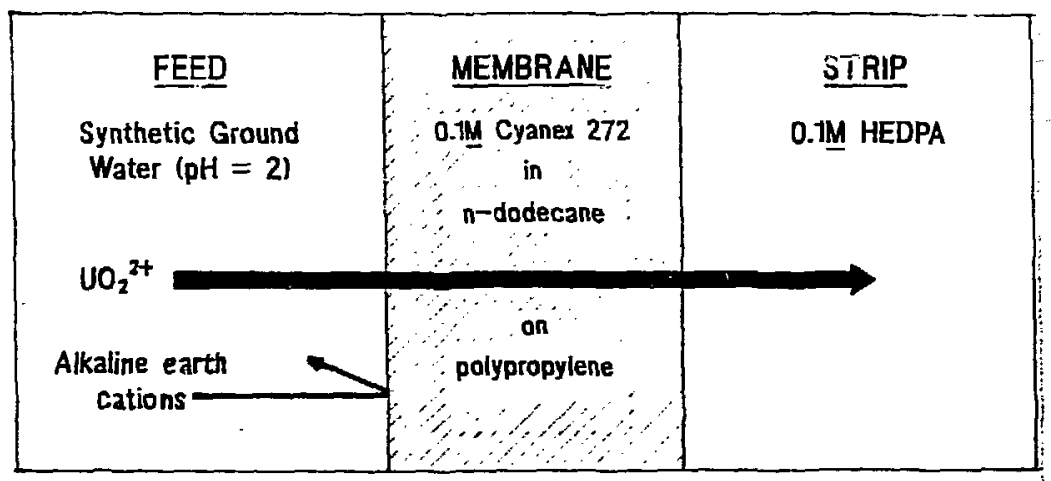




$$
=2
$$

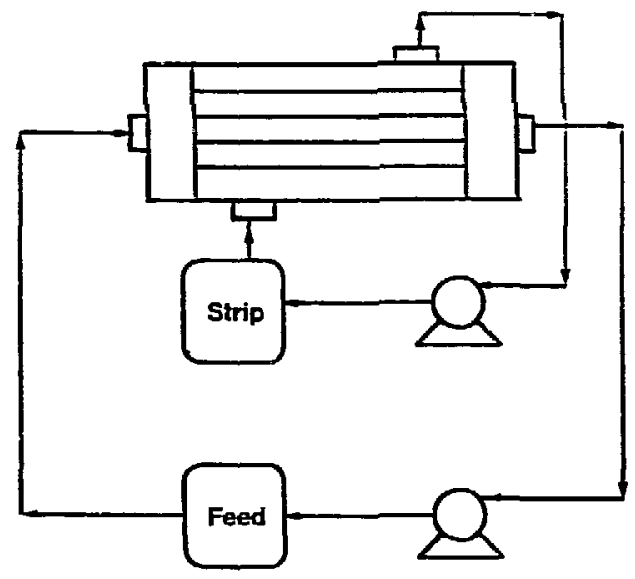




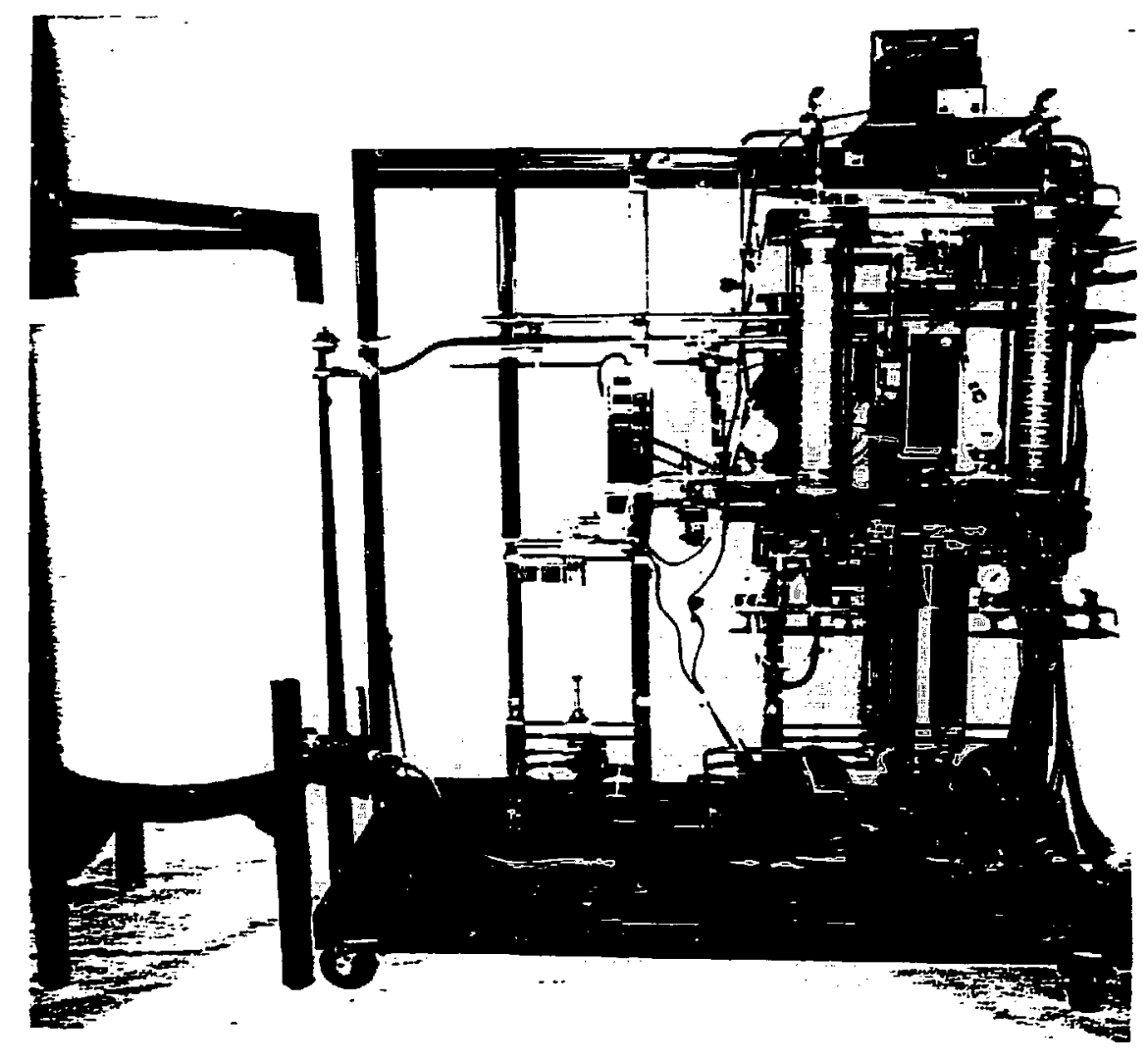




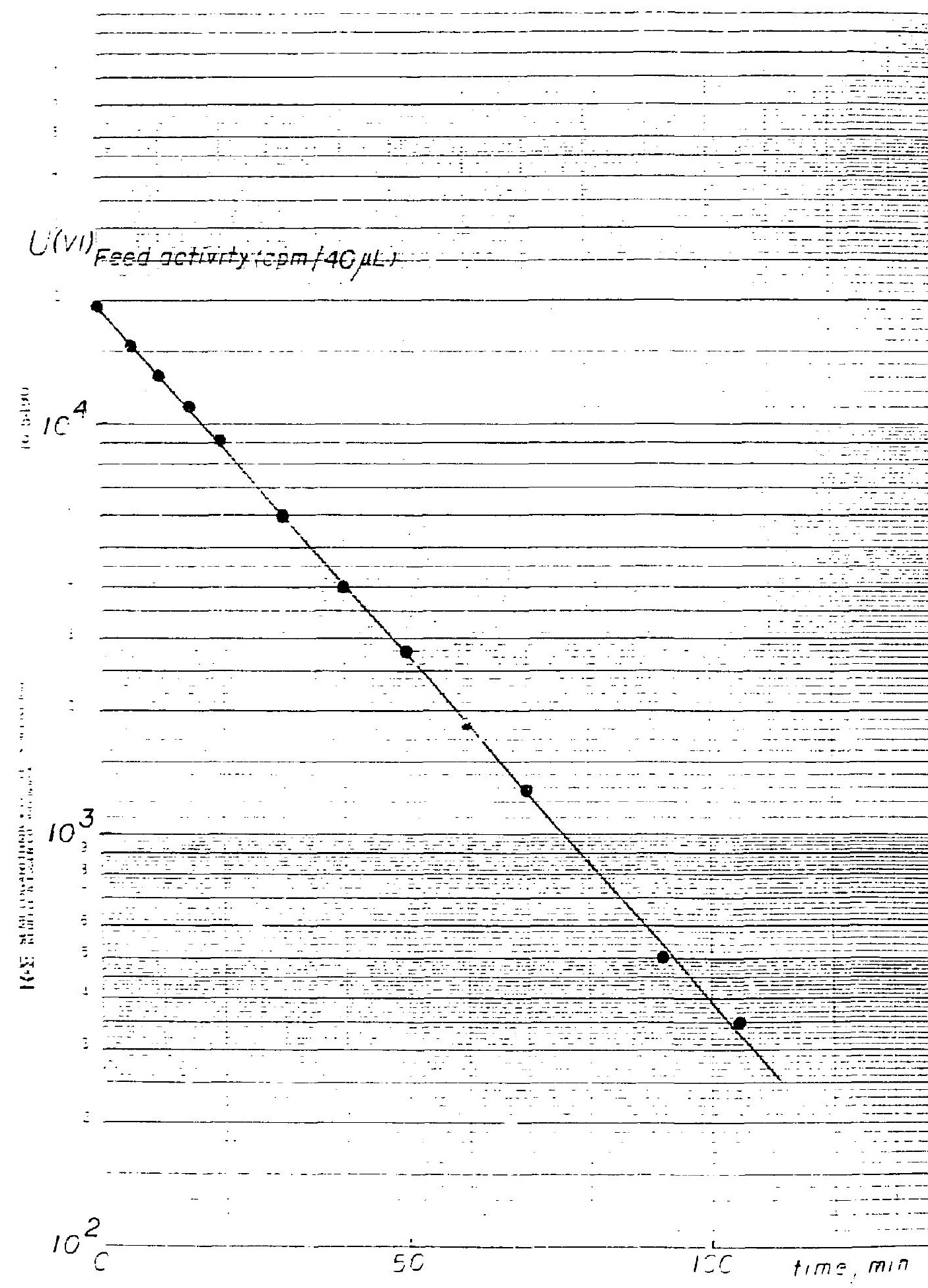




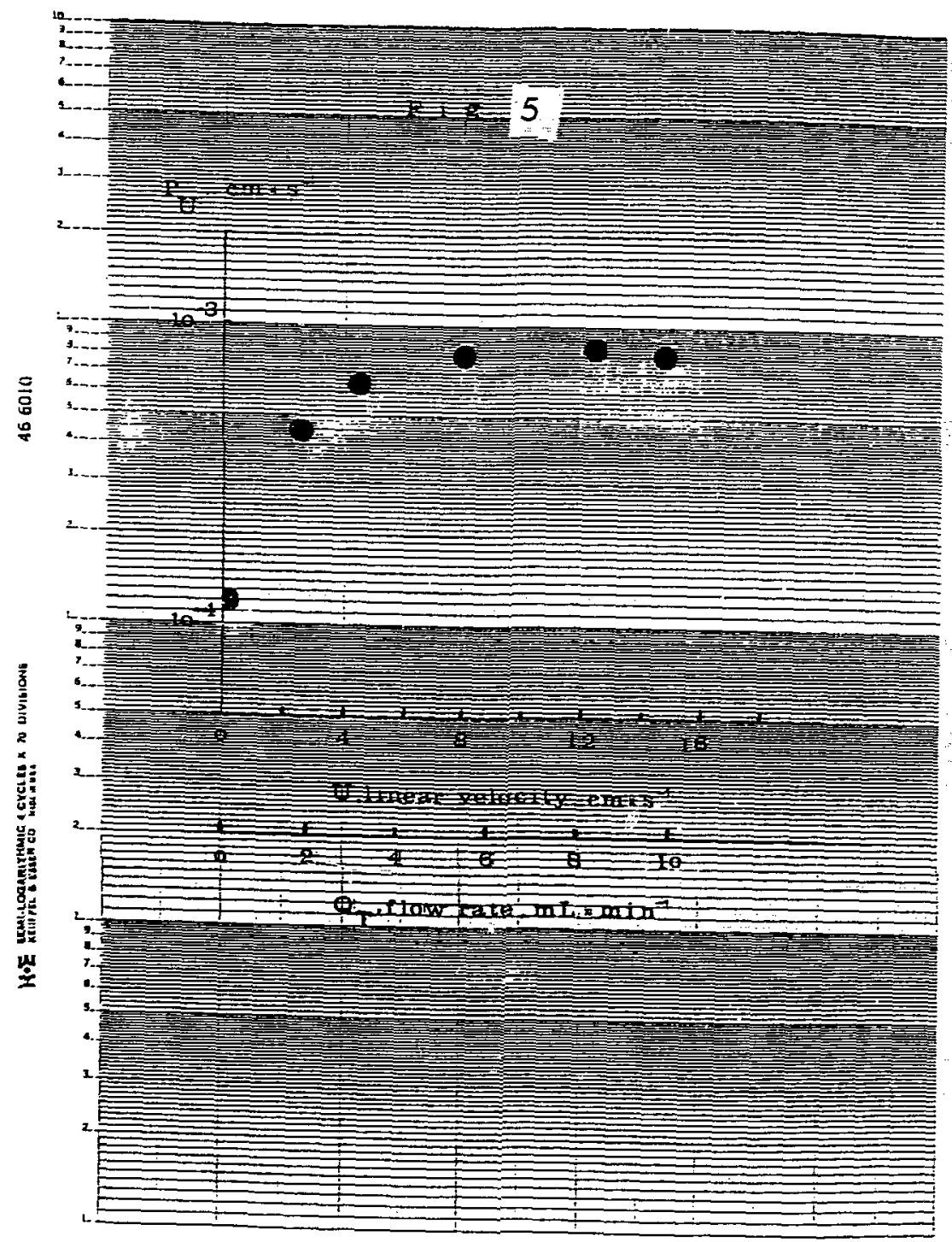




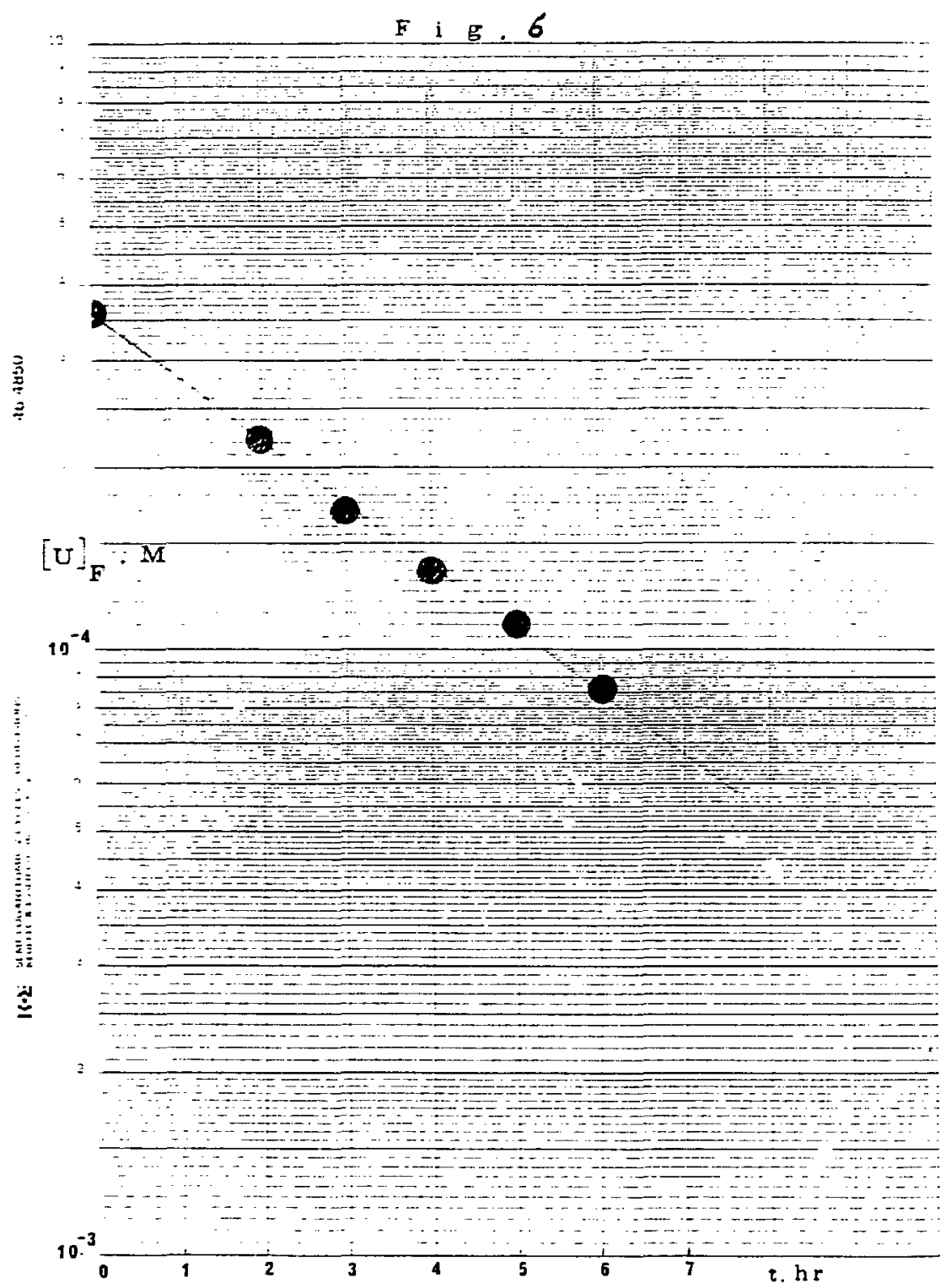




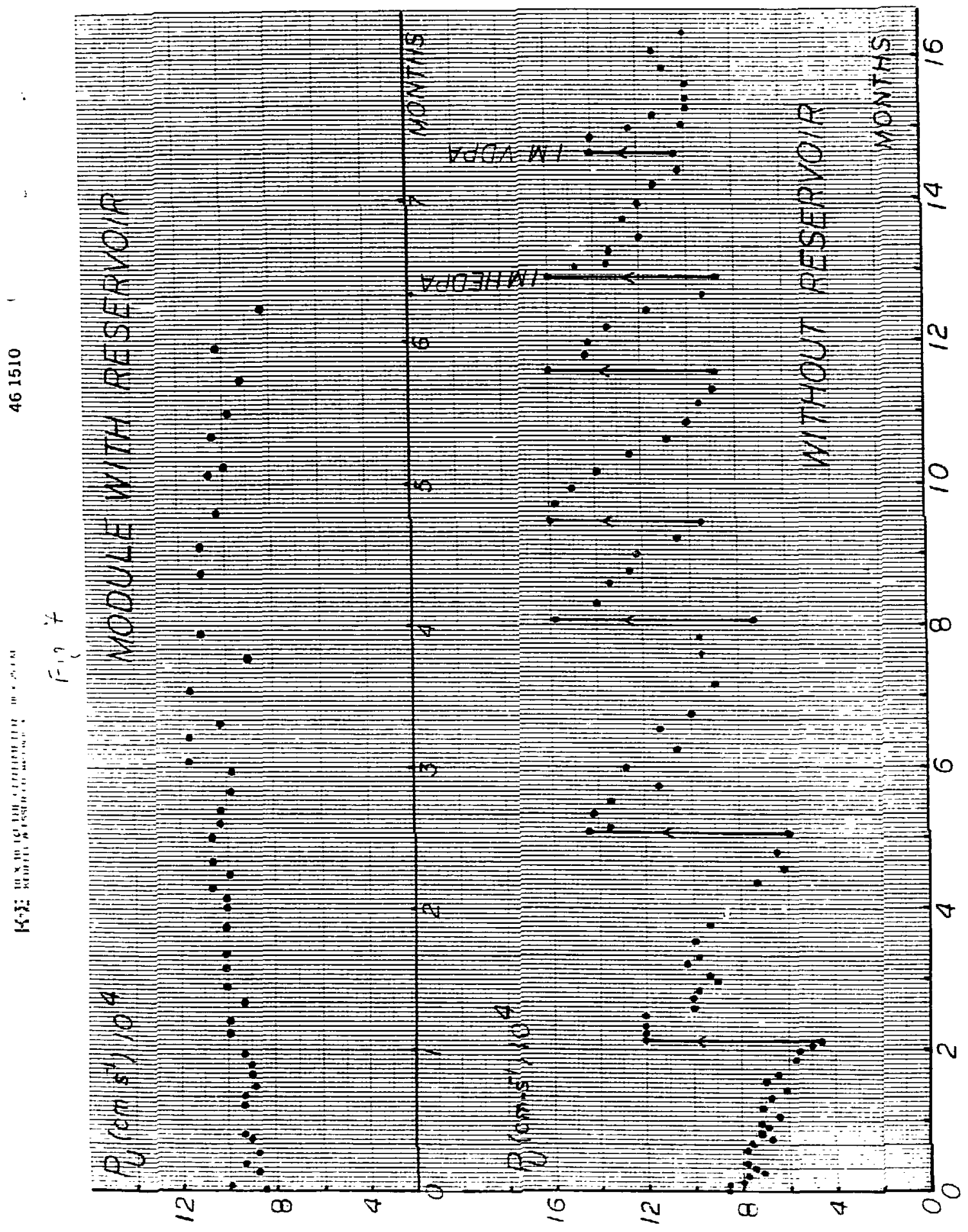




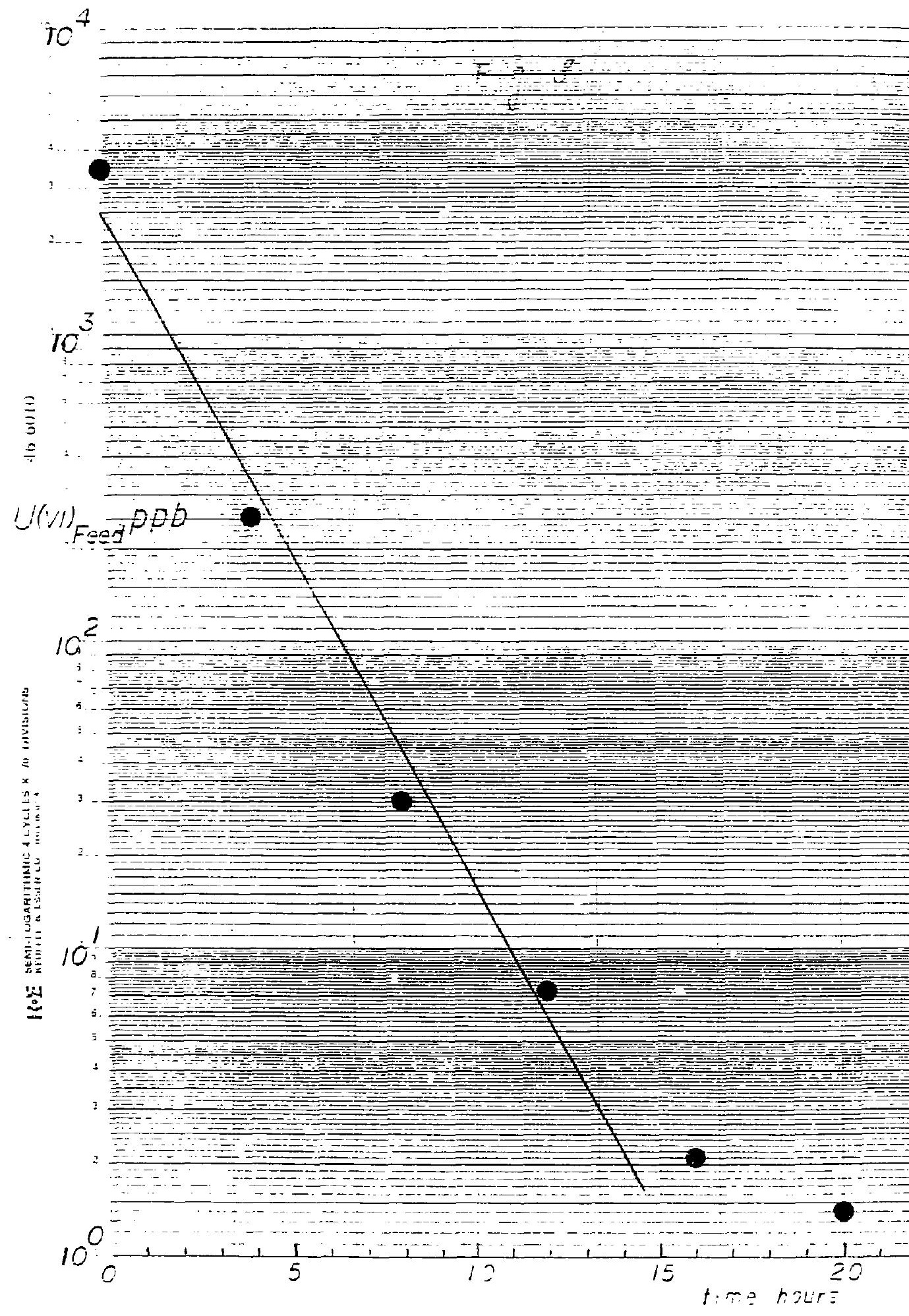

